\title{
BMJ Open Do emissions from landfill fires affect pregnancy outcomes? A retrospective study after arson at a solid waste facility in Sicily
}

Walter Mazzucco, ${ }^{\oplus 1,2}$ Elisa Tavormina, ${ }^{3}$ Maurizio Macaluso, ${ }^{4,5}$ Claudia Marotta, ${ }^{\odot 1}$ Rosanna Cusimano, ${ }^{2}$ Davide Alba, ${ }^{1}$ Claudio Costantino, ${ }^{1}$ Rosario Grammauta, ${ }^{6}$ Achille Cernigliaro, ${ }^{3}$ Salvatore Scondotto, ${ }^{3}$ Francesco Vitale $e^{1,2}$

To cite: Mazzucco W,

Tavormina E, Macaluso M, et al. Do emissions from landfill fires affect pregnancy outcomes? A retrospective study after arson at a solid waste facility in Sicily. BMJ Open 2019:9:e027912. doi:10.1136/ bmjopen-2018-027912

- Prepublication history and additional material is published online only. To view please visit the journal online (http://dx.doi. org/10.1136/bmjopen-2018027912).

WM and MM contributed equally.

Received 14 November 2018 Revised 19 June 2019 Accepted 19 June 2019
Check for updates

(C) Author(s) (or their employer(s)) 2019. Re-use permitted under CC BY-NC. No commercial re-use. See rights and permissions. Published by BMJ.

For numbered affiliations see end of article.

Correspondence to

Dr. Claudia Marotta;

marotta.claudia@gmail.com

\section{ABSTRACT}

Objectives In response to public health concern about effects of arson at solid waste management plants in July 2012, we analysed vital statistics data to evaluate any potential effect on pregnancies at different gestational ages of pollutants emitted from the landfill on fire.

Setting A community living near the largest landfill plant in Sicily.

Participants The study group comprised 551 births, live births and stillbirths from pregnancies of mothers residing in the extra-urban exposed area, conceived during a

40 week period during which the highest fire's peak might have influenced pregnancy.

Primary and secondary outcome measures Birth outcomes (gestational age $<37$ and $<32$ weeks, low birth weight, very low birth weight and small for gestational age) in the study group were compared with the ones of a reference group of women residing in areas of Sicily with similarly low population density and industrial development.

Results Among singleton live births we observed a three-fold increase in risk of very preterm birth between the extra-urban area and the remaining low inhabitants density and unindustrialised areas for births whose pregnancies were in the third trimester (OR adjusted for maternal age and infant gender $=3.41 ; 95 \% \mathrm{Cl} 1.04$ to 11.16). There was an excess of very low birth weight singleton infants in the study group as compared with the reference group, which was limited to births to mothers exposed during periconception period (OR adjusted for maternal age and infant gender $=4.64 ; 95 \% \mathrm{Cl} 1.04$ to 20.6) and first trimester (OR adjusted for maternal age and infant gender=3.66; $95 \% \mathrm{Cl} 1.11$ to 12.1). The association estimates were imprecise due to the small number of outcomes recorded.

Conclusions The study documented an excess of very preterm and very low birth weight among infants born to mothers exposed to the landfill fire emissions during conception or early pregnancy.

\section{INTRODUCTION}

The number of studies investigating the potential human health effects on communities of
Strengths and limitations of this study

- Arson at an urban solid waste facility allowed us to investigate the potential reproductive health effects of short-term exposure to pollutants emitted from the combustion of solid waste.

- The analysis of vital records data allowed us to assess birth outcomes of pregnancies exposed at distinct stages of development, from conception to the time of delivery.

- Data obtained from the regional Certificate of Birth Attendance registry allowed comparing exposed and non-exposed groups employing standardised information on birth outcomes.

- The retrospective design and the limited vital statistics data available for analysis did not allow a detailed assessment of the longitudinal nature of the exposure-response relation, or a precise adjustment for potential confounding.

- As it is often the case in studies of local environmental exposure events, the number of relevant outcomes was limited, especially when stratified according to the stage of the pregnancy at exposure, and association estimates were imprecise.

pollutants released from landfills or incinerators is increasing, ${ }^{12}$ showing that exposure is weakly associated with a variety of adverse health outcomes, including cancer, adverse reproductive outcomes and birth defects. $^{3-5}$ Increased risk of low birth weight and congenital malformations has been reported in communities living in proximity to landfills. ${ }^{2}{ }^{6}$ Maternal exposure to incinerator emissions was associated with preterm delivery. ${ }^{7}$ A study of exposure to incinerator emissions containing dioxin concluded that exposure had little impact on birth weight and sex ratio, but may have been associated with gestational age at delivery. ${ }^{8}$ Inconsistent findings across studies may be due to design issues, lack of exposure information, use of 
indirect surrogate measures, acute versus long-term exposure conditions and inadequate control of confounding. ${ }^{9}$ Variation in risk perception among the stakeholders makes it difficult to communicate about the available evidence.

In Italy, the incidence of fires in solid waste management plants is increasing, ${ }^{10}$ addressing the need to investigate the potential health effects of short-term exposure to pollutants emitted from the combustion of solid waste.

In Sicily, the fourth most populated Italian region, 5 million residents produce about 6000 tons of solid waste daily, which are disposed of in four municipal solid waste landfills (MSW-L). ${ }^{11}$ The largest MSW-L is located in Bellolampo at 450 metres above sea level, on the hidden side of a mountain at the south-western border of Palermo (the largest city in Sicily, with 700000 inhabitants, and its administrative capital). ${ }^{11}$ The Bellolampo MSW-L collects solid waste from the Palermo metropolitan area, which includes the city and nearby municipalities. ${ }^{12}$ On 29 July, 2012, a fire started at multiple points within the landfill and emissions spread to a large populated area, causing concern for the public's health. Emissions peaked in the first 24 hours and decreased thereafter, until the fire was fully extinguished by 16 August, 2012 .

We analysed vital statistics data to retrospectively evaluate the potential effects of the arson on the outcomes of pregnancies that were exposed to the emissions at different gestational ages.

\section{METHODS}

In response to the arson, the Sicilian Regional Health Authority defined an administrative area around the landfill, whose resident population was considered as potentially exposed to the MSW-L emissions and placed under surveillance (online supplementary file) ${ }^{13}$ Environmental monitoring of the area ${ }^{14}$ was done through existing stationary monitoring stations. ${ }^{15}$ A longitudinal retrospective study was designed to study the effects of exposure to the fire emissions on reproductive health outcomes. We obtained limited data from the regional Certificate of Birth Attendance (CedAP) registry, which collects information on all births to women of childbearing age (10 to 55 years old) who deliver in Sicily, including parental sociodemographic characteristics, obstetrical history, prenatal care and characteristics of pregnancy and birth. The CedAP registry does not include data on births to resident mothers who delivered outside the region or wanted to preserve anonymity $(0.4 \%)$. Date of conception was estimated using the date of birth and gestational age at birth reported in the registry. The study included all live births and stillbirths to mothers residing within the surveillance zone, whose estimated conception date occurred from 36 weeks prior to the peak of the fire (from 2:00 PM on 29 July, 2012, to 2:00 PM on 30 July, 2012), until 4 weeks after the fire. To remove confounding by exposure to pollutants deriving from anthropic activities and vehicular traffic within metropolitan areas, we restricted the main focus of the analysis to residents of the extra-urban section of the surveillance area (online supplementary file). Thus, the study group included all live births and stillbirths in the extra-urban surveillance area from pregnancies that were potentially exposed to the fire around the time of conception as well as pregnancies that were exposed at later stages (through the $36^{\text {th }}$ week). The reference group comprised all live births and stillbirths to mothers residing in the remaining extraurban, low-density and unindustrialised areas of Sicily, during the same time interval. To distinguish pregnancy periods of susceptibility to acute exposure to the fire emissions, we stratified the study group and the reference population according to the following four subperiods of exposure (figure 1): (i) periconception (conception occurring on 29 July, 2012, or up to 4 weeks later), (ii) first trimester (conception date 12 to 0 weeks before 29 July, 2012), (iii) second trimester (24 to 13 weeks before 29 July, 2012), (iv) third trimester (36 to 25 weeks before 29 July, 2012).

For each stage of the pregnancy at the time of exposure, we compared birth outcomes of the study group with those of the reference group. We also carried out internal comparisons within the study group, contrasting outcomes across the four subperiods of exposure.

We conducted two supplementary analyses: first, we compared birth outcomes to mothers in the metropolitan area of Palermo (the main metropolitan area served by the Bellolampo MSW-L, 656829 inhabitants) with those to mothers residing in the two other Sicilian metropolitan areas (Catania, 293104 inhabitants, and Messina, 242914 inhabitants) in the same study period. Second, to assess any systematic difference between the study group and the reference group independently from the fire, we repeated the comparison using data on births that occurred during the year preceding the arson (specifically, births conceived within -36 and +4 weeks from 29 July, 2011).

For each comparison, we evaluated the following proportions, defined according to European guidelines for perinatal statistics adopted by the PERISTAT system ${ }^{16}{ }^{17}$ : (a) among all births (ie, live births and stillbirths combined): proportion of stillbirths, proportions of male and female births and proportions of singleton and multiple births; (b) among live births: preterm birth (gestational age $<37$ weeks), very preterm birth (gestational age $<32$ weeks), low birth weight $(<2500$ grams), very low birth weight $(<1500$ grams) and small for gestational age (SGA) (birth weight under the $10^{\text {th }}$ percentile of the national distribution of birth weights of the same gestational age or birth of gestational age $\geq 37$ weeks weighing $<2500$ grams).

Because of CedAP data flow at the time in study was relatively new, we were only able to use the limited information described in this manuscript.

To make statistical inference about the comparisons between the different study groups and the references, we used logistic regression to estimate OR and 95\% CI of the ORs, with and without adjusting for maternal age 


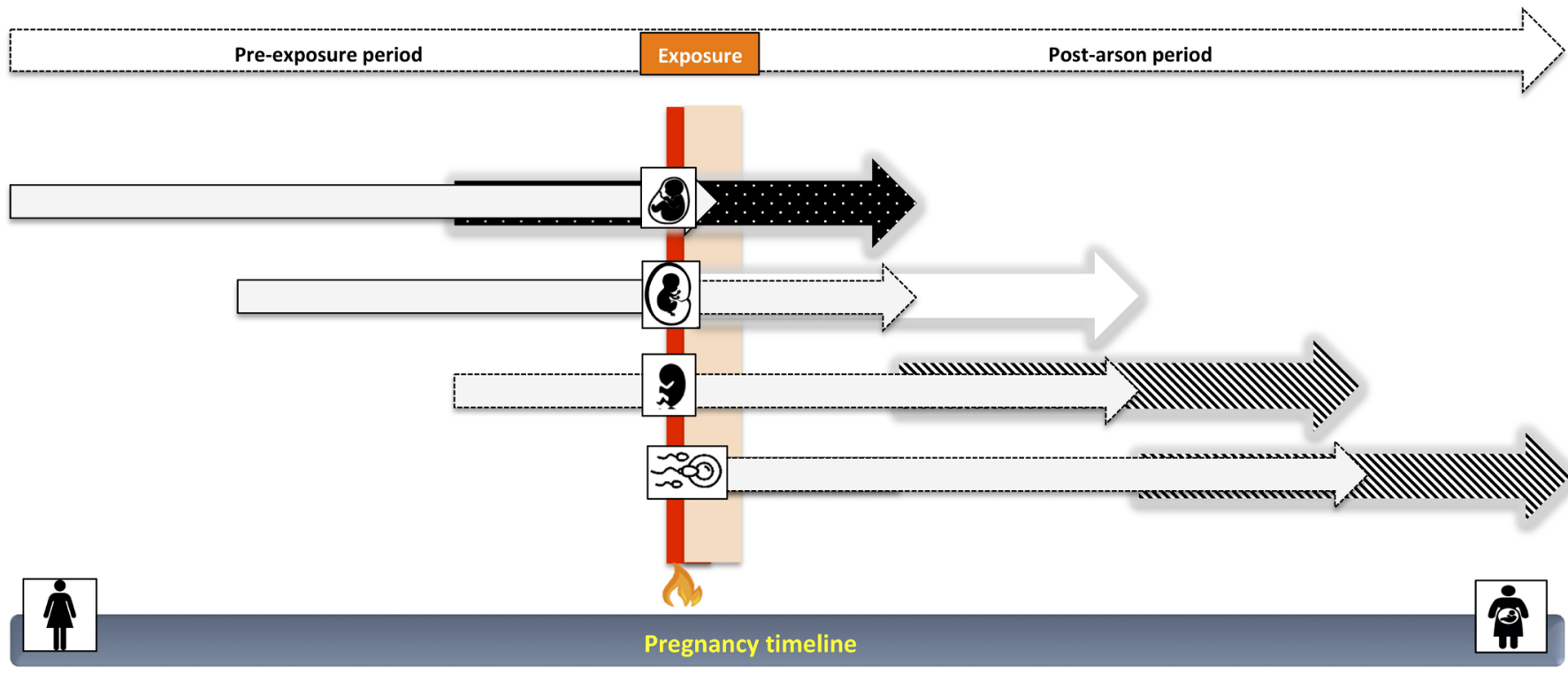

III Trimester of pregnancy (25- 36 weeks)

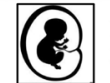

rimester of pregnancy (13-24 weeks)
4 weeks after the arson onset (multi-site fire estinguishing period)

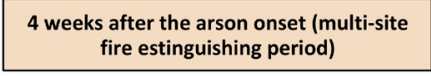

( I Trimester of pregnancy ( 0 -12 weeks)
Peri-conception

HEALTH OUTCOMES ASSOCIATED TO THE EXPUSURE
Arson onset and highest peak emissions

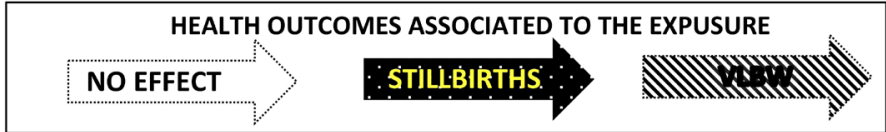

Figure 1 Bellolampo solid waste landfill arson: pregnancy stage at exposure among resident mothers and key statistically significant findings documented for the extra-urban area (the arrows represent the health outcomes associated to the exposure to the pollutants emitted by the arson).

and infant gender, the only two potential confounders made available to us. Throughout this paper we treated the OR as an estimate of the risk ratio. This is appropriate as the absolute risks for most of the outcomes considered are well below $10 \%$, and under these conditions the OR closely approximates the relative risk. Statistical analyses were carried out using STATA (V.11.2 MP, StataCorp, College Station, Texas). Strengthening the Reporting of Observational Studies in Epidemiology guidelines were followed for research reporting.

\section{Patient and public involvement}

Patients were not involved.

\section{RESULTS}

Mothers residing in the exposed extra-urban area (the study group) gave birth to a total of 551 infants (548 live born +3 stillborn) conceived during the interval of interest (20/11/2011 to 26/08/2012). There were 22341 births (22264 live births +65 stillbirths) from pregnancies conceived during the same period by mothers residing in the remaining Sicilian low population-density, low industrialisation areas (the comparison group). We observed a two-fold increase in risk of very preterm birth (OR adjusted for maternal age and infant gender $=2.29 ; 95 \%$ CI 1.12 to 4.68 ) and a two-fold increase in risk of very low birth weight (OR adjusted for maternal age and infant gender $=2.20$; $95 \%$ CI 1.02 to 4.72 ) among singleton live births (table 1).

Among all births, we observed differences between the study group and the comparison group that were limited to births whose pregnancies were in the third trimester when the fire began: a two-fold excess of multiple births (OR adjusted by gender $=2.42 ; 95 \%$ CI 1.38 to 4.24 ) and a four-fold excess of stillbirths (OR adjusted by gender $=4.69$; 95\% CI 1.40 to 15.6) (table 2).

Among singleton live births we observed a three-fold increase in risk of very preterm between the extra-urban area and the remaining Sicilian low inhabitants density and unindustrialised areas for births whose pregnancies were in the third trimester (OR adjusted for maternal age and infant gender $=3.41 ; 95 \%$ CI 1.04 to 11.16 ) when the fire began (table 2).

Among singleton live births there were differences in very low birth weight rates between the extra-urban area and the remaining Sicilian low inhabitants density and unindustrialised areas for births whose pregnancies were either in periconception period (OR adjusted for maternal age and infant gender $=4.64 ; 95 \%$ CI 1.04 to 20.6) or in the first trimester (OR adjusted for maternal age and infant gender $=3.66 ; 95 \%$ CI 1.11 to 12.1 ) when the fire began (table 2). Additional analyses of the risk of 
Table 1 Outcomes of 551 births from pregnancies to mothers residing in the extra-urban area (study group) and of 22342 births from pregnancies to Sicilian women residing in similar low population density, low industrialisation areas (comparison group), conceived between 36 weeks before and 4 weeks after 29 July, 2012

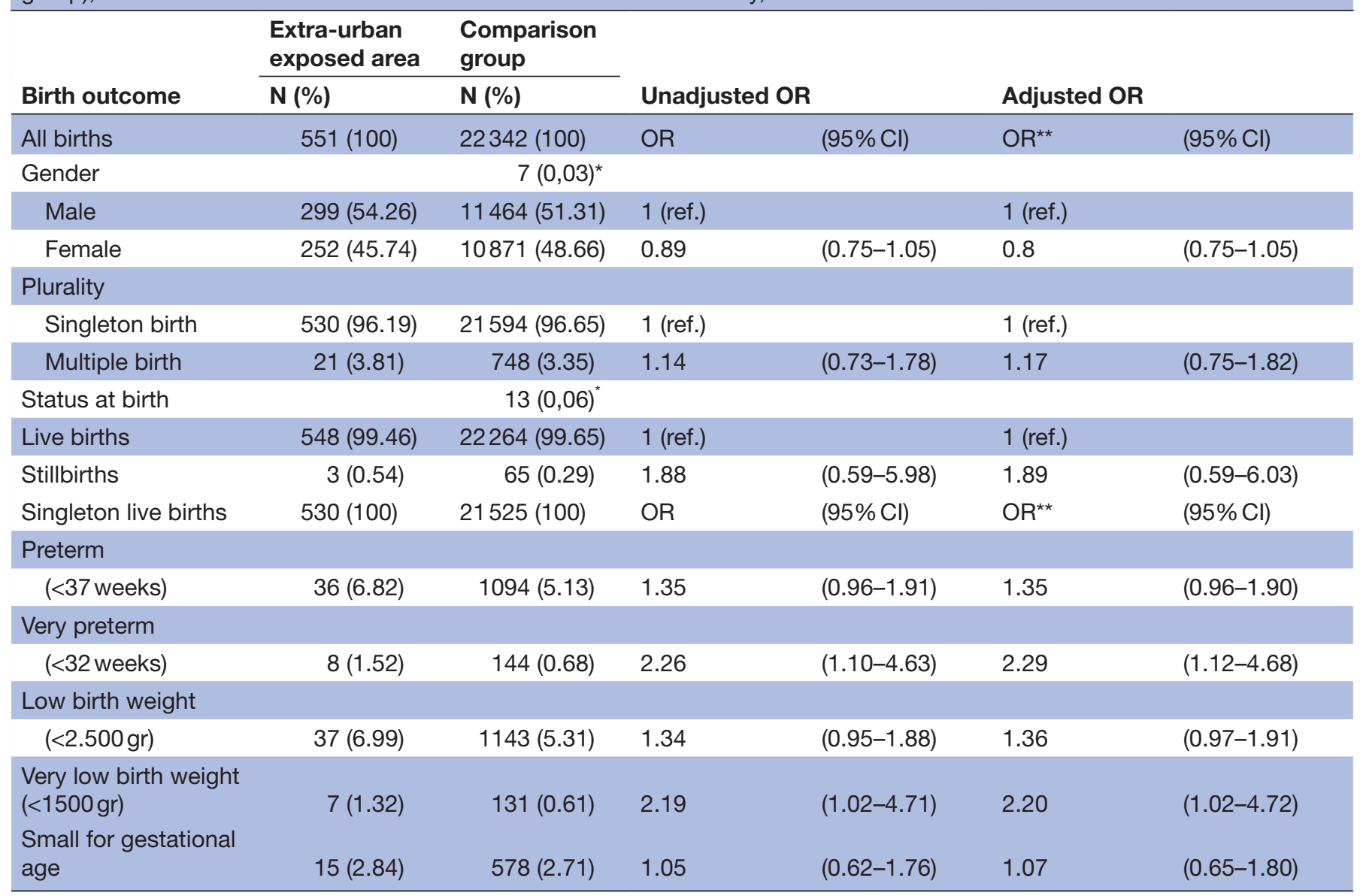

${ }^{\star}$ Number and percentage of non-missing values ${ }^{\star \star}$ OR adjusted for maternal age and infant gender (OR contrasting male and female gender adjusted for maternal age, only).

very low birth weight stratified by gestational age revealed that the excess of very low birth weight overlapped only in part with very preterm birth: remarkably, the infants accounting for the excess of very low birth weight from pregnancies conceived around the time of exposure were born after 32 weeks of gestation (results not shown in detail). Internal comparisons of the susceptibility period within the extra-urban exposed group did not reveal clear differences between subgroups defined by stages of the pregnancy at the time of exposure, but these comparisons were hampered by the small size of the study group (results not shown).

Our supplementary analyses did not show differences between the outcomes of 4653 births to mothers residing in the Palermo metropolitan area which were conceived between 36 weeks before and 4 weeks after 29 July, 2012, and the outcomes of 3980 births to mothers residing in the other Sicilian metropolitan areas conceived during the same time interval (table 3). Similarly, we observed no differences between the outcomes of births from pregnancies to mothers residing in the extra-urban exposed area and the outcomes of births from pregnancies to
Sicilian women residing in low population-density, low-industrialisation areas of Sicily, conceived between 36 weeks before and 4 weeks after 29 July, 2011 (1 year before the arson) (table 4).

\section{DISCUSSION}

This retrospective study investigated birth outcomes among women residing near one of the largest Italian solid waste landfills (the Bellolampo MSW-L), who were pregnant during a fire that started on 29 July, 2012, and lasted for about a 2 week period before being completely extinguished.

As compared with births occurring during the same interval to mothers residing in other areas of Sicily with similar population density and level of industrialisation, we observed statistically significant differences suggesting that the landfill arson could have had an adverse impact on pregnancy outcomes. Our secondary analysis did not highlight statistically significant differences between the metropolitan exposed area and the other metropolitan populations in Sicily. In the study group, the analysis 


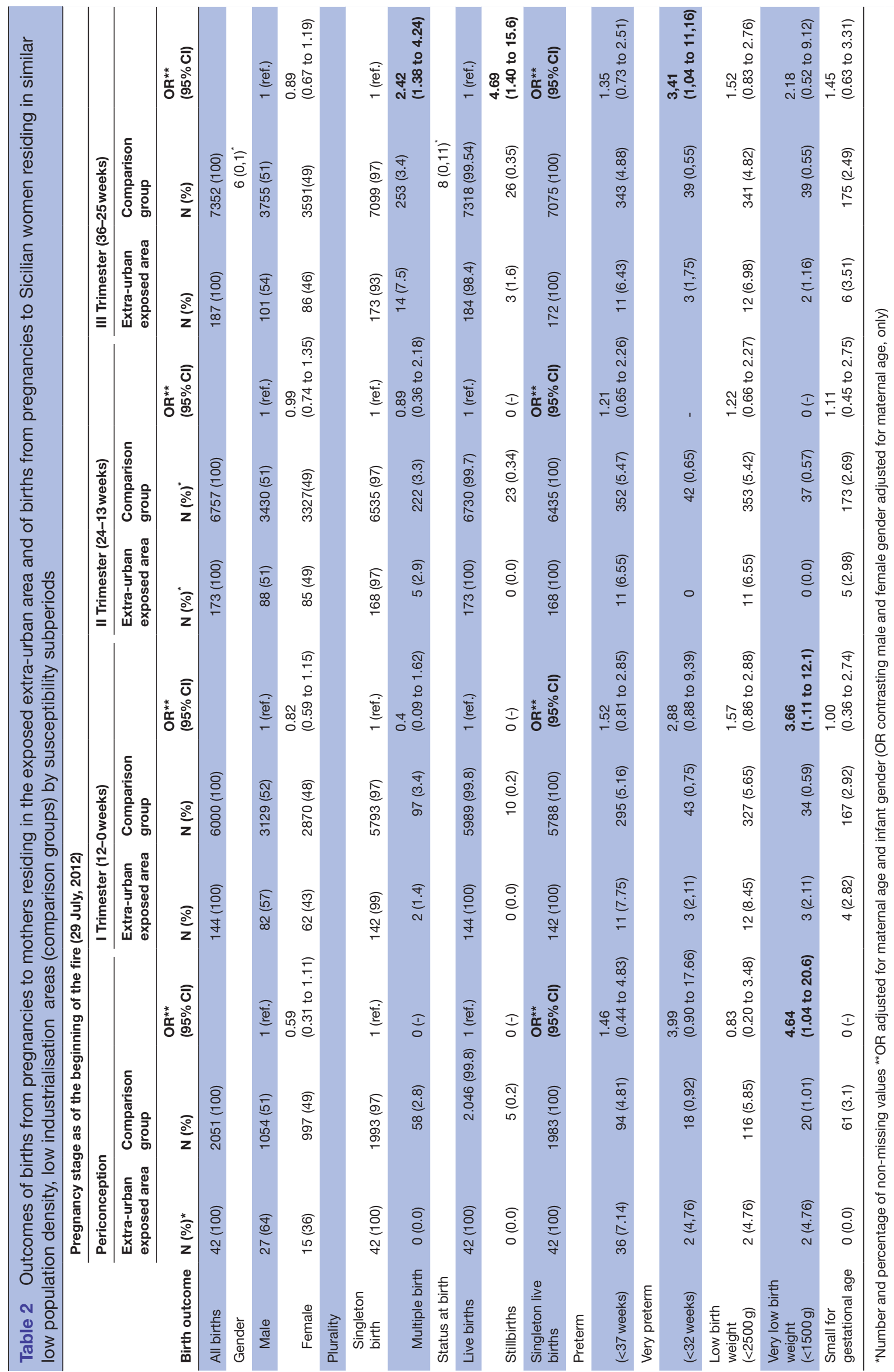

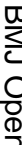

$\overrightarrow{\overrightarrow{0}}$

흘

$\vec{\circ}$

$\overrightarrow{\vec{\omega}}$

응.

ก่̀

is

ฮै

운

高

$\stackrel{\text { O }}{0}$

○ 
Table 3 Outcomes of 4653 births from pregnancies to mothers residing in the Palermo metropolitan area and of 3980 births from pregnancies to Sicilian women residing in the remaining metropolitan areas (comparison group), conceived between 36 weeks before and 4 weeks after 29 July, 2012

\begin{tabular}{|c|c|c|c|c|c|c|}
\hline \multirow{3}{*}{$\begin{array}{l}\text { Birth outcome } \\
\text { All births }\end{array}$} & \multirow{3}{*}{$\begin{array}{l}\begin{array}{l}\text { Palermo } \\
\text { exposed } \\
\text { metropolitan } \\
\text { area }\end{array} \\
\mathbf{N}(\%) \\
4653(100)\end{array}$} & \multirow{3}{*}{$\begin{array}{l}\begin{array}{l}\text { Remaining } \\
\text { metropolitan } \\
\text { areas } \\
\text { (Catania and } \\
\text { Messina) }\end{array} \\
\mathbf{N}(\%) \\
3980(100) \\
\end{array}$} & \multirow{2}{*}{\multicolumn{2}{|c|}{ Unadjusted OR }} & \multirow{2}{*}{\multicolumn{2}{|c|}{ Adjusted OR }} \\
\hline & & & & & & \\
\hline & & & OR & $(95 \% \mathrm{Cl})$ & $\mathrm{OR}^{*}$ & $(95 \% \mathrm{Cl})$ \\
\hline \multicolumn{7}{|l|}{ Gender } \\
\hline Male & 2350 (50.51) & $2040(51.26)$ & 1 (ref.) & & 1 (ref.) & \\
\hline Female & 2303 (49.49) & $1940(48.74)$ & 1.03 & (0.94 to 1.12$)$ & 1.03 & (0.94 to 1.12$)$ \\
\hline \multicolumn{7}{|l|}{ Plurality } \\
\hline Singleton birth & 4492 (96.54) & $3829(96.21)$ & 1 (ref.) & & 1 (ref.) & \\
\hline Multiple birth & $161(3.46)$ & 151 (3.79) & 0.91 & (0.72 to 1.14$)$ & 0.91 & (0.72 to 1.14$)$ \\
\hline \multicolumn{7}{|l|}{ Status at birth } \\
\hline Live births & 4636 (99.63) & 3966 (99.65) & 1 (ref.) & & 1 (ref.) & \\
\hline Stillbirths & $17(0.37)$ & $14(0.35)$ & 1.04 & (0.51 to 2.11 ) & 1.03 & (0.51 to 2.10$)$ \\
\hline Singleton live births & $4492(100)$ & $3829(100)$ & OR & $(95 \% \mathrm{Cl})$ & $\mathrm{OR}^{*}$ & $(95 \% \mathrm{Cl})$ \\
\hline \multicolumn{7}{|l|}{ Preterm } \\
\hline (<37 weeks) & $169(7.25)$ & $111(6.75)$ & 1.08 & (0.84 to 1.38 ) & 1.08 & (0.84 to 1.39$)$ \\
\hline \multicolumn{7}{|l|}{ Low birth weight } \\
\hline (<2.500 gr) & $146(6.74)$ & $180(7.15)$ & 0.86 & (0.69 to 1.08 ) & 0.86 & (0.69 to 1.08$)$ \\
\hline $\begin{array}{l}\text { Very low birth weight } \\
\text { (<1500 gr) }\end{array}$ & $25(1.07)$ & $21(0.83)$ & 1.28 & (0.72 to 2.30$)$ & 1.28 & (0.72 to 2.30$)$ \\
\hline Small for gestational age & $59(2.53)$ & $66(4.01)$ & 0.62 & (0.43 to 0.89 ) & 0.62 & (0.64 to 1.77$)$ \\
\hline
\end{tabular}

*OR adjusted for maternal age and infant gender (OR contrasting male and female gender adjusted for maternal age, only)

documented a three-fold excess risk of very preterm birth ( $<32$ weeks, OR adjusted for maternal age and infant gender $=3.41 ; 95 \%$ CI 1.04 to 11.16$)$ and a two-fold excess risk of very low birth weight $(<1500 \mathrm{~g})$ among singleton live births. The effect on very low birth weight appeared to be concentrated among births whose conception date was between 12 weeks prior to the beginning of the fire to 4 weeks after, suggesting that the largest impact of the exposure may have been on pregnancies that were conceived during the fire (OR adjusted for maternal age and infant gender $=4.64 ; 95 \%$ CI 1.04 to 20.6) or were exposed to the fire during the first trimester (OR adjusted for maternal age and infant gender $=3.66 ; 95 \%$ CI 1.11 to 12.1). On the other hand, the effect on the risk of very preterm birth did not appear to be confined to any particular subgroup at risk. These findings are compatible with a toxic effect on placentation or early embryo development leading to restricted intrauterine growth and premature delivery. ${ }^{18}$ Maternal exposure to ambient concentrations of air pollutants, particularly to fine particulate matter, has been identified as a risk factor for preterm birth, low birth weight and SGA births. ${ }^{20}$ Multiple studies have documented an association between fine particulate exposure and preterm birth. ${ }^{21-23}$
Exposure to wildfires has been proposed as a risk factor for preterm birth ${ }^{20}$ and reduced average birth weight. ${ }^{24} 25$

In a multisite Italian study, maternal exposure to incinerator emissions was associated with preterm delivery even at very low levels. ${ }^{7}$ Moreover, a study conducted in Taiwan concluded that exposure to emissions from an incinerator generating dioxin had little effects on birth weight and female birth, but may have a modest effect on gestational age. 8

The mechanisms proposed to explain the effect of fine particulate exposure on preterm birth include oxidative stress, pulmonary and placental inflammation, coagulopathy, endothelial dysfunction and haemodynamic responses, ${ }^{20}{ }^{26}$ as well as intrauterine inflammation. ${ }^{20}$ Of interest, adverse pregnancy outcomes including preterm delivery, intrauterine growth restriction and impaired infant weight gain are associated with exposure to polychlorinated dibenzo-p-dioxins, polychlorinated dibenzofurans and dioxin-like PCBs (DL-PCBs). ${ }^{1}$ Recently, The Hokkaido Study on Environment and Children's Health has demonstrated the effects of environmental chemical exposures (dioxins, polychlorinated biphenyls (PCB), organochlorine pesticides, perfluoroalkyl substances, phthalates, bisphenol A and methylmercury) 
Table 4 Outcome of 536 births from pregnancies to mothers residing in the exposed extra-urban area and of 23373 births from pregnancies to Sicilian women residing in low inhabitants density and unindustrialised areas of Sicily (comparison group), conceived between 36 weeks before and 4 weeks after July 29, 2011 (the same calendar period during the previous year)

\section{Extra-urban Comparison exposed area group}

\begin{tabular}{|c|c|c|c|c|c|c|}
\hline \multirow{2}{*}{$\begin{array}{l}\text { Birth outcome } \\
\text { All births }\end{array}$} & \multirow{2}{*}{$\begin{array}{r}\mathbf{N}(\%) \\
536(100)\end{array}$} & \multirow{2}{*}{$\begin{array}{l}\mathbf{N}(\%) \\
23373(100)\end{array}$} & \multicolumn{2}{|c|}{ Unadjusted OR } & \multicolumn{2}{|l|}{ Adjusted OR } \\
\hline & & & OR & (95\% Cl) & $\mathrm{OR}^{*}$ & $(95 \% \mathrm{Cl})$ \\
\hline \multicolumn{7}{|l|}{ Gender } \\
\hline Male & $272(50.75)$ & $12041(51.52)$ & 1 (ref.) & & 1 (ref.) & \\
\hline Female & $264(49.25)$ & $11329(48.57)$ & 1.03 & $(0.87-1.22)$ & 1.03 & $(0.87-1.22)$ \\
\hline \multicolumn{7}{|l|}{ Plurality } \\
\hline Singleton birth & $520(97.01)$ & 22632 (96.83) & 1 (ref.) & & 1 (ref.) & \\
\hline Multiple birth & $16(2.99)$ & $741(3.17)$ & 0.94 & $(0.57-1.56)$ & 0.96 & $(0.58-1.58)$ \\
\hline \multicolumn{7}{|l|}{ Status at birth } \\
\hline Live births & 534 (99.63) & 23291 (99.65) & 1 (ref.) & & 1 (ref.) & \\
\hline Stillbirths & $2(0.37)$ & $79(0.34)$ & 1.10 & $(0.27-4.50)$ & 1.10 & $(0.27-4.50)$ \\
\hline Singleton live births & & & OR & $(95 \% \mathrm{Cl})$ & $\mathrm{OR}^{*}$ & $(95 \% \mathrm{Cl})$ \\
\hline \multicolumn{7}{|l|}{ Preterm } \\
\hline (<37 weeks) & $30(5.78)$ & $1226(5.44)$ & 1.06 & $(0.731-1.54)$ & 1.07 & $(0.74-1.55)$ \\
\hline \multicolumn{7}{|l|}{ Low birth weight } \\
\hline$(<2.500 \mathrm{gr})$ & $35(6.74)$ & $1226(5.44)$ & 1.26 & $(0.88-1.78)$ & 1.26 & $(0.89-1.79)$ \\
\hline $\begin{array}{l}\text { Very low birth weight } \\
(<1500 \mathrm{gr})\end{array}$ & $4(0.77)$ & $133(0.59)$ & 1.31 & $(0.48-3.55)$ & 1.31 & $(0.48-3.56)$ \\
\hline $\begin{array}{l}\text { Small for gestational } \\
\text { age }\end{array}$ & 15 (2.89) & $616(2.75)$ & 1.05 & $(0.62-1.77)$ & 1.05 & $(0.63-1.77)$ \\
\hline
\end{tabular}

${ }^{*}$ OR adjusted for maternal age and infant gender (OR contrasting male and female gender adjusted for maternal age, only)

on genetically susceptible populations and on DNA methylation, ${ }^{27} 28$ while other research suggests that exposure to tetrachlorodibenzo- $p$-dioxin (TCDD) may induce shifts in the immune response that enhance a proinflammatory phenotype at the maternal-foetal interface, increasing the risk of infection-mediated preterm birth. ${ }^{29}$

The body of published evidence, taken together with the statistically significant excess risk concentrated in a relatively narrow period of susceptibility, lends credibility to the hypothesis that the Bellolampo arson adversely affected pregnancies exposed during conception or in the first trimester, causing an excess of deliveries of very low birth weight infants in the extra-urban area.

The study also documented in the same area a significant four-fold excess of stillbirths among pregnancies that were exposed to the landfill fire during the third trimester. This finding is based on a total of three stillbirths that occurred in the extra-urban study group, all of which were concentrated to the subgroup exposed during the third trimester, and it is possible that the observed excess is due to chance even if it was statistically significant. On the other hand, long-term exposure to PCBs was associated with increased proportions of miscarriage and stillbirth in animal studies, ${ }^{30}$ and exposure to emissions from solid-waste incinerators was associated with increased risk of miscarriage in an epidemiological study in Italy. ${ }^{31}$
Thus, the excess of stillbirths to mothers exposed during the third trimester could be associated with the arson.

The excess of multiple births from pregnancies exposed during the third trimester in the study group is unlikely to be caused by exposure to the landfill fire, as plurality must have been established long before the arson. The literature provides conflicting evidence on the association between exposure to air pollution from incinerators and multiple births. ${ }^{32}$

Long-term exposure of the study area to pollutants (independently from the fire) was already known and was confirmed by the detection of TCDD and heavy metals at concentrations above the limits permitted by law ${ }^{33}$ in subsoil samples collected by the regional environment protection agency after the fire. ${ }^{34}$ However, the secondary analysis comparing birth outcomes in the same extraurban groups in the year before the arson did not highlight any potential effect related to a long-term exposure to pollutants emitted from the landfill.

The findings of this study should be interpreted in light of some limitations. First, the retrospective design and the analysis of data from vital statistics do not allow a detailed assessment of the longitudinal nature of the exposure-response relation, or precise adjustment for potential confounding. Although environmental monitoring was performed in response to the arson, we had 
limited access to the data and could only confirm the increase in air particulate concentrations after the beginning of the fire. Thus, we could not assess specific exposure levels of individual pregnancies at multiple points in time. Lastly, as it is often the case in studies of local environmental exposure events, the outcomes of interest were limited in number, especially when stratified according to the stage of the pregnancy at exposure. Nevertheless, the observations made in this study are of general interest. While previous studies conducted in Italy have suggested associations between exposure to incinerator emissions and increased risk of miscarriages and preterm births, ${ }^{31}$ to our knowledge, the present study is the first in Europe to investigate the effects of exposure emissions on birth outcomes evaluating pregnancies exposed at different stages of development. Despite the limited information base and sample size, the excess of very low birth weight infants achieved statistical significance and was confined to early-stage pregnancies.

The study adds to the growing body of evidence that exposure to emissions from solid waste landfill operations may have serious health effects and underscores the need for monitoring potential hazards and health outcomes in the resident population..$^{35}$ The arsons at the Bellolampo MSW-L, ${ }^{36}$ as well as the ones that occurred in other Italian solid waste treatment plants in proximity to populated areas, ${ }^{10}$ and the public concern they caused, exemplify the important role that integration of environmental monitoring and epidemiological surveillance may have in this realm. ${ }^{37-39}$ The questionable strength of the evidence collected in this and in similar studies also underscores the need for better planning of monitoring and surveillance activities (more detailed exposure information, better definition and monitoring of reproductive and other health outcomes, assessment of long-term effects and better control for potential confounders) and highlights the difficulty of conveying results to the various stakeholders $^{9}$ and the related need for effective methods to transfer study results to policymakers and the public. ${ }^{40}$

Finally, our study highlights the importance to promote an integrated management of urban solid waste alternatives to landfills, including waste to energy plants or other newly available technologies such as pyrolysis and gasification. $^{41}$

\section{Author affiliations}

${ }^{1}$ Health Promotion Sciences, Maternal and Infant Care, Internal Medicine and Medical Specialties (PROMISE) Department, University of Palermo, Palermo, Sicilia, Italy

${ }^{2}$ Clinical Epidemiology and Cancer Registry Unit, Palermo University Hospital "P. Giaccone", Palermo, Italy

${ }^{3}$ Department of Health Services and Epidemiological Observatory, Regional Health Authority, Palermo, Italy

${ }^{4}$ Division of Biostatistics and Epidemiology, Cincinnati Children's Hospital Medical Centre, Cincinnati, Ohio, USA

${ }^{5}$ Department of Paediatrics, University of Cincinnati College of Medicine, Cincinnati, Ohio, USA

${ }^{6}$ Institute for the Study of Anthropogenic Impacts and Sustainability in the Marine Environment (IAS), National Research Council, National Research Council, Torretta Granitola (Trapani), Italy
Contributors All individuals listed as authors have contributed substantially to designing, performing or reporting the study and every specific contribution is indicated as follows. Conception and design of the study: WM, MM, RC, AC. Data collection: ET, AC, SS. Statistical analysis: ET, AC, RG, MM, WM. Interpretation of data: CC, CM, WM, MM, AC, ET. Manuscript writing and drafting: WM, MM, CM, AC, DA. Revision of the manuscript: WM, CM, MM, SS, FV. Approval of the final version of the manuscript: WM, ET, MM, CM, RC, DA, CC, RG, AC, SS, FV.

Funding The authors have not declared a specific grant for this research from any funding agency in the public, commercial or not-for-profit sectors.

Competing interests None declared.

Patient consent for publication Not required.

Provenance and peer review Not commissioned; externally peer reviewed.

Data sharing statement No additional data available.

Open access This is an open access article distributed in accordance with the Creative Commons Attribution Non Commercial (CC BY-NC 4.0) license, which permits others to distribute, remix, adapt, build upon this work non-commercially, and license their derivative works on different terms, provided the original work is properly cited, appropriate credit is given, any changes made indicated, and the use is non-commercial. See: http://creativecommons.org/licenses/by-nc/4.0/.

\section{REFERENCES}

1. Vrijheid M. Health effects of residence near hazardous waste landfill sites: a review of epidemiologic literature. Environ Health Perspect 2000;108(suppl 1):101-12.

2. Saunders P. A systematic review of the evidence of an increased risk of adverse birth outcomes in populations living in the vicinity of landfill waste disposal sites. Population health and waste management: scientific data and policy options. Report of a WHO workshop Rome, Italy, 29-30 March 2007 Edited by: Mitis F, Martuzzi M. Copenhagen: WHO, Regional Office for Europe, 2007:25-7.

3. Williams FL, Lawson AB, Lloyd OL. Low sex ratios of births in areas at risk from air pollution from incinerators, as shown by geographical analysis and 3-dimensional mapping. Int J Epidemiol 1992;21:311-9.

4. Dummer TJ, Dickinson HO, Parker L. Adverse pregnancy outcomes around incinerators and crematoriums in Cumbria, north west England, 1956-93. J Epidemiol Community Health 2003;57:456-61.

5. Cordier S, Chevrier C, Robert-Gnansia E, et al. Risk of congenital anomalies in the vicinity of municipal solid waste incinerators. Occup Environ Med 2004;61:8-15.

6. Elliott P, Richardson S, Abellan JJ, et al. Geographic density of landfill sites and risk of congenital anomalies in England. Occup Environ Med 2009;66:81-9.

7. Candela S, Ranzi A, Bonvicini L, et al. Air pollution from incinerators and reproductive outcomes: a multisite study. Epidemiology 2013;24:863-70.

8. Lin CM, Li CY, Mao IF. Birth outcomes of infants born in areas with elevated ambient exposure to incinerator generated PCDD/Fs. Environ Int 2006;32:624-9.

9. Porta D, Milani S, Lazzarino Al, et al. Systematic review of epidemiological studies on health effects associated with management of solid waste. Environ Health 2009;8:60.

10. Regioni.it. Incendi negli impianti di smaltimento rifiuti: il $20 \%$ è doloso. 2018. Available http://www.regioni.it/newsletter/n-3303/ del-17-01-2018/incendi-negli-impianti-di-smaltimento-rifiuti-il-20-edoloso-17570/ (accessed 3 Feb 2018).

11. ISTAT. National Institute for Statistics) Population Data. http://demo. istat.it/ (accessed 3 Feb 2018).

12. Di Bella G, Di Trapani D, Viviani G. Evaluation of methane emissions from Palermo municipal landfill: Comparison between field measurements and models. Waste Manag 2011;31:1820-6.

13. UNINETLAB - University of Palermo, ARPA Sicily (Sicilian Regional Environmental Protection Agency). Studio per la valutazione della dispersione di contaminanti in atmosfera in seguito all'incendio nella discarica di Bellolampo avvenuta dal 29 Luglio al 17 Agosto. 2012. Available http://www.arpa.sicilia.it/wp-content/uploads/2014/03/ Allegato_3.pdf (accessed 3 Feb 2018).

14. Sicilian Regional Health Authority. Department of health activities and epidemiological observatory. D.D.G n01690/2012, adopted on 29.08.2012 with regard to "Zona di protezione da diossina nell'area di Bellolampo (Palermo). Misure sanitarie per la sicurezza alimentare.

15. Sicilian Region Environmental Department; ARPA Sicily (Sicialian Regional Environmental Protection Agency). Sistema di Rilevamento Regionale della Qualità dell'Aria della Regione Sicilia. Progetto di Razionalizzazione del monitoraggio della qualità dell'aria in Sicilia 
e relativo Programma di Valutazione (art.5, comma 6, del Decreto Legislativo 13 agosto 2010, n.155). 2014

16. Zeitlin J, Wildman K, Bréart G, et al. PERISTAT: indicators for monitoring and evaluating perinatal health in Europe. Eur $J$ Public Health 2003:13:29-37.

17. Mazzucco W, Cusimano R, Macaluso M, et al. A retrospective follow up study on maternal age and infant mortality in two Sicilian districts. BMC Public Health 2011;11:817.

18. Maisonet M, Correa A, Misra D, et al. A review of the literature on the effects of ambient air pollution on fetal growth. Environ Res 2004;95:106-15.

19. Srám RJ, Binková B, Dejmek J, et al. Ambient air pollution and pregnancy outcomes: a review of the literature. Environ Health Perspect 2005;113:375-82.

20. Shah PS, Balkhair T. Air pollution and birth outcomes: A systematic review. Environ Int 2011;37:498-516.

21. Qian Z, Liang S, Yang S, et al. Ambient air pollution and preterm birth: A prospective birth cohort study in Wuhan, China. Int J Hyg Environ Health 2016;219:195-203.

22. Ha S, Hu H, Roussos-Ross D, et al. The effects of air pollution on adverse birth outcomes. Environ Res 2014;134:198-204.

23. Fleischer NL, Merialdi M, van Donkelaar A, et al. Outdoor air pollution, preterm birth, and low birth weight: analysis of the world health organization global survey on maternal and perinatal health. Environ Health Perspect 2014;122:425-30.

24. Holstius DM, Reid CE, Jesdale BM, et al. Birth weight following pregnancy during the 2003 Southern California wildfires. Environ Health Perspect 2012;120:1340-5.

25. Rich DQ, Liu K, Zhang J, et al. Differences in birth weight associated with the 2008 beijing olympics air pollution reduction: results from a natural experiment. Environ Health Perspect 2015;123:880-7.

26. Kannan S, Misra DP, Dvonch JT, et al. Exposures to airborne particulate matter and adverse perinatal outcomes: a biologically plausible mechanistic framework for exploring potential effect modification by nutrition. Environ Health Perspect 2006;114:1636-42.

27. Nachman RM, Mao G, Zhang X, et al. Intrauterine Inflammation and Maternal Exposure to Ambient PM2.5 during Preconception and Specific Periods of Pregnancy: The Boston Birth Cohort. Environ Health Perspect 2016;124:1608-15.

28. Kishi R, Araki A, Minatoya M, et al. The Hokkaido Birth Cohort Study on Environment and Children's Health: cohort profile-updated 2017. Environ Health Prev Med 2017;22:46.
29. Peltier MR, Arita Y, Klimova NG, et al. 2,3,7,8-tetrachlorodibenzo-pdioxin (TCDD) enhances placental inflammation. $J$ Reprod Immunol 2013;98(1-2):10-20.

30. Tsukimori K, Tokunaga S, Shibata S, et al. Long-term effects of polychlorinated biphenyls and dioxins on pregnancy outcomes in women affected by the Yusho incident. Environ Health Perspect 2008;116:626-30.

31. Candela S, Bonvicini L, Ranzi A, et al. Exposure to emissions from municipal solid waste incinerators and miscarriages: a multisite study of the MONITER Project. Environ Int 2015;78:51-60.

32. Lloyd OL, Lloyd MM, Williams FL, et al. Twinning in human populations and in cattle exposed to air pollution from incinerators. Br J Ind Med 1988;45:556-60.

33. Legislative decree n. 152 of 2006. Norme in materia ambientale 2006.

34. ARPA Sicily (Sicilian Regional Environmental Protection Agency). Studio preliminare sullo stato di qualità dei comparti ambientali (suolo e acque sotterranee) all'esterno della discarica di Bellolampo. Available. 2012 http://www.arpa.sicilia.it/wp-content/uploads/2014/ 03/Allegato_1.pdf (accessed 3 Feb 2018).

35. Domingo JL, Rovira J, Vilavert L, et al. Health risks for the population living in the vicinity of an Integrated Waste Management Facility: screening environmental pollutants. Sci Total Environ 2015;518519:363-70. C:363-370.

36. Marchese I. Maxi incendio nella discarica di Bellolampo. Giornale di Sicilia 2015. Available http://palermo.gds.it/2015/07/08/maxiincendio-nella-discarica-di-bellolampo-minacciata-dalle-fiamme-lasesta-vasca_379946/ (accessed 3 Feb 2018).

37. Barchitta M, Fragapane S, Quattrocchi A, et al. Environmental health risk communication in the case "Terra dei Fuochi": content analysis of online newspaper articles. Ann Ig 2015;27:30-8.

38. Mazzucco W, Cusimano R, Zarcone M, et al. Funnel plots and choropleth maps in cancer risk communication: a comparison of tools for disseminating population-based incidence data to stakeholders. BMJ Open 2017;7:e011502.

39. Mazzucco W, Cusimano R, Mazzola S, et al. Childhood and Adolescence Cancers in the Palermo Province (Southern Italy): Ten Years (2003-2012) of Epidemiological Surveillance. Int J Environ Res Public Health 2018;15:1344.

40. Briggs DJ. A framework for integrated environmental health impact assessment of systemic risks. Environ Health 2008;7:61.

41. Cotana F, Messineo A, Petrozzi A, et al. Comparison of ORC Turbine and Stirling Engine to Produce Electricity from Gasified Poultry Waste. Sustainability 2014;6(9):5714-29. 